\title{
Effect of feed restriction on the maintenance energy requirement of broiler breeders
}

\author{
Guilherme Ferreira da Silva Teofilo ${ }^{1}$, Rony Riveros Lizana ${ }^{1}$, Rosiane de Souza Camargos ${ }^{1}$, \\ Bruno Balbino Leme ${ }^{1}$, Freddy Alexander Horna Morillo ${ }^{1}$, Raully Lucas Silva ${ }^{1}$, \\ João Batista Kochenborger Fernandes ${ }^{1}$, and Nilva Kazue Sakomura ${ }^{1 \text {,* }}$
}

\section{* Corresponding Author: \\ Nilva Kazue Sakomura \\ Tel: +55-16-99709-5757, \\ Fax: +55-16-3209-7503, \\ E-mail: nilva.sakomura@unesp.br}

1 Department of Animal Science, Faculty of Agricultural and Veterinarian Sciences of São Paulo State University - UNESP, JaboticabalSP, 14884-900, Brazil

\section{ORCID}

Guilherme Ferreira da Silva Teofilo https://orcid.org/0000-0002-6485-1504 Rony Riveros Lizana

https://orcid.org/0000-0002-1629-4328

Rosiane de Souza Camargos

https://orcid.org/0000-0001-5641-3793

Bruno Balbino Leme

https://orcid.org/0000-0002-1644-1973

Freddy Alexander Horna Morillo

https://orcid.org/0000-0002-1277-0120

Raully Lucas Silva

https://orcid.org/0000-0002-4810-3362

João Batista Kochenborger Fernandes

https://orcid.org/0000-0003-3886-8561

Nilva Kazue Sakomura

https://orcid.org/0000-0001-5707-4113

Submitted Apr 19, 2021; Revised Jun 11, 2021; Accepted Sept 21, 2021
Objective: This study aimed to evaluate the effect of the ad libitum and restricted feeding regimen on fasting heat production (FHP) and body composition.

Methods: Twelve Hubbard broilers breeders were selected with the same body weight and submitted in two feeding regimes: Restricted (T1) with feed intake of $150 \mathrm{~g} / \mathrm{bird} / \mathrm{d}$ and ad libitum (T2). The birds were randomly distributed on the treatments in two runs with three replications per treatment (per run). The birds were adapted to the feed regimens for ten days. After that, they were allocated in the open-circuit chambers and kept for three days for adaptation. On the last day, oxygen consumption $\left(\mathrm{VO}_{2}\right)$ and carbon dioxide production $\left(\mathrm{VCO}_{2}\right)$ were measured by $30 \mathrm{~h}$ under fasting. The respiratory quotient $(\mathrm{RQ})$ was calculated as the $\mathrm{VCO}_{2} / \mathrm{VO}_{2}$ ratio, and the heat production $(\mathrm{HP})$ was obtained using the Brower equation (1985). The FHP was estimated throughout the plateau of HP 12 hours after the feed deprivation. The body composition was analyzed by dual-energy X-ray absorptiometry scanning at the end of each period. Data were analyzed for one-way analysis of variance using the Minitab software.

Results: The daily feed intake was $30 \mathrm{~g}$ higher to T2 $(\mathrm{p}<0.01)$ than the T1. Also, the birds of the T2 had significatively $(\mathrm{p}<0.05)$ more oxygen consumption $\left(+3.1 \mathrm{~L} / \mathrm{kg}^{0.75} / \mathrm{d}\right)$ and $\mathrm{CO}_{2}$ production $\left(+2.2 \mathrm{~L} / \mathrm{kg}^{0.75} / \mathrm{d}\right)$. That resulted in a higher FHP $359 \pm 14 \mathrm{~kJ} / \mathrm{kg}^{0.95} / \mathrm{d}$ for T2 than T1 $296 \pm 17.23 \mathrm{~kJ} / \mathrm{kg}^{0.75} / \mathrm{d}$. In contrast, the RQ was not different between treatments, with an average of 0.77 for the fasting condition. In addition, protein and fat composition were not affected by the treatment, while a tendency $(p<0.1)$ was shown to higher bone mineral content on the T1.

Conclusion: The birds under ad libitum feeding had a higher maintenance energy requirement but their body composition was not affected compared to restricted feeding.

Keywords: Basal Metabolic Rate; Fasting Heat Production; Feed Regimen

\section{INTRODUCTION}

The genetic selection to the fast growth of broilers resulted in a proportional increase of feed intake by broiler breeders, causing a greater intake of nutrients and energy above the energy requirements for production and maintenance [1]. The high feed intake increases the fat deposition, carrying to body weight (BW) increase [2-4]. Due to higher feed intake, several metabolic disturbances can occur and reduce egg production, fertility, and hatchability [2-5]. According to Renema and Robinson [6], to reduce the excessive weight gain and incidence of reproductive disorders, broiler breeders must be submitted to restricted feeding programs. This feeding system aims to meet birds' nutritional requirements by providing reduced feed to control the weight variation and favour sexual development $[2,7]$. For this, the calculation of dietary nutrients must consider the amount of feed allo- 
cated, obtaining an adequate balance of nutrients and energy [8]. Also, adequate body composition should be achieved so the birds can withstand high reproductive rates [9]. In this way, limiting the regulation of feed intake according to their nutritional needs becomes critical. It depends exclusively on the feeding strategies adopted by specialists.

On the other hand, ad libitum feeding can be an alternative, where the diets' energy and nutritional density must be adjusted (qualitative restriction) to prevent over-feeding. Still, this feeding system presents several disadvantages, once the weight and body composition variations lead to alteration in the dynamic of energy metabolism and, consequently, in maintenance utilization $[10,11]$. Therefore, it was hypothesized that the feed regimen, depending on the previous feed intake level, affects the maintenance requirement measured throughout fasting heat production (FHP).

The determination of energy requirement for maintenance through the FHP [12] was barely described in poultry, and principally it was estimated with ad libitum fed birds. Thus, there is little information available to broiler breeders. Based on this, the broad understanding of bird's metabolic variations on feed restriction will favour the correct determination of maintenance, supporting future studies in the dynamic of energy metabolism studies in broiler breeders.

We aimed to evaluate the effect of feed regimen (restricted and ad libitum) on the FHP in broiler breeders in the production phase and describe their body components variation (protein, lipids, and minerals).

\section{MATERIALS AND METHODS}

\section{Facilities and animal management}

The study was conducted at the Poultry Science Laboratory (LAVINESP) at São Paulo State University, Campus Jaboticabal-SP. The animal utilization, management, and procedures were approved by The Ethics Committee on Animal Use (CEUA) of the Faculdade de Ciências Agrárias e Veterinárias, UNESP, Jaboticabal, São Paulo, Brazil under protocol no. 013079/19.

The assay was carried out using thirty Hubbard broiler breeders of 30 week-old. During the pre-experimental period, birds were individually allocated in cages to evaluate their productive performance. Twelve birds were selected at the peak of production from this group according to the BW and laying rate. The environmental temperature was adjusted to maintain around $22^{\circ} \mathrm{C} \pm 2^{\circ} \mathrm{C}$ to guarantee thermal comfort, and the light program was adopted to provide $16 \mathrm{~L}: 8 \mathrm{D}$.

During the pre-experimental period, the diet mash-type was daily provided in the morning $(8: 00 \mathrm{~h})$ in a controlled manner $(150 \mathrm{~g} / \mathrm{bird})$, and in the afternoon $(16: 00 \mathrm{~h})$ the egg production was recorded. In addition, the birds were individually weighed each week. The basal diet was formulated to meet or exceed the nutritional requirements of birds (12.21 metabolizable energy $\mathrm{MJ} / \mathrm{kg}$ and 15.5 crude protein).

\section{Experimental design and procedure}

The selected birds were randomly distributed in two treatments according to feed regimen. T1, Restricted feeding (150 $\mathrm{g} / \mathrm{bird} / \mathrm{d}$ ); and T2, ad libitum feeding (feed allocation of 300 $\mathrm{g} / \mathrm{bird} / \mathrm{d}$, amount of feed sufficient to guarantee that the feeder would not be empty until the next feed supply).

Six birds per run were allocated individually in respirometry chambers for gas exchange measurements (oxygen consumption, $\mathrm{VO}_{2}$; and carbon dioxide production, $\mathrm{VCO}_{2}$ ). The indirect calorimetry system in our laboratory consists of six chambers on an intermittent reading throughout the day. For that reason, the measurement was divided into two runs with an interval of two weeks between runs. Hence the data collection was executed in two different runs with three replications per treatment in each run according to the following protocol (Figure 1): adaptation period to the chambers ( $3 \mathrm{~d}$ ), measurement of heat production after the feed was withdrawal in fasting condition (24 h).

\section{Indirect calorimetry and heat production calculation} The indirect calorimetry facilities consist of an open-circuit system, with six chambers (dimension: $90 \times 85 \times 95 \mathrm{~cm}$ ) equipped with an environmental temperature controller and a Sable System Classic Line (Sable System, North Las Vegas, NV, USA) pumps and gas analyzer detailed in Figure 2. The

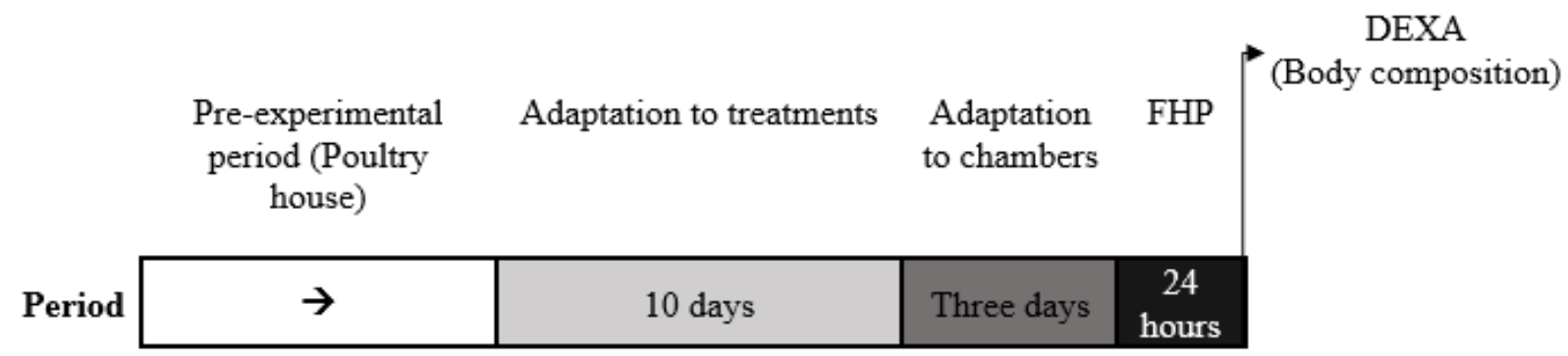

Figure 1. Protocol of experimental period for adaptation (treatments and chambers), and measurements. FHP, fasting heat production; DEXA, dual-energy X-ray absorptiometry. 


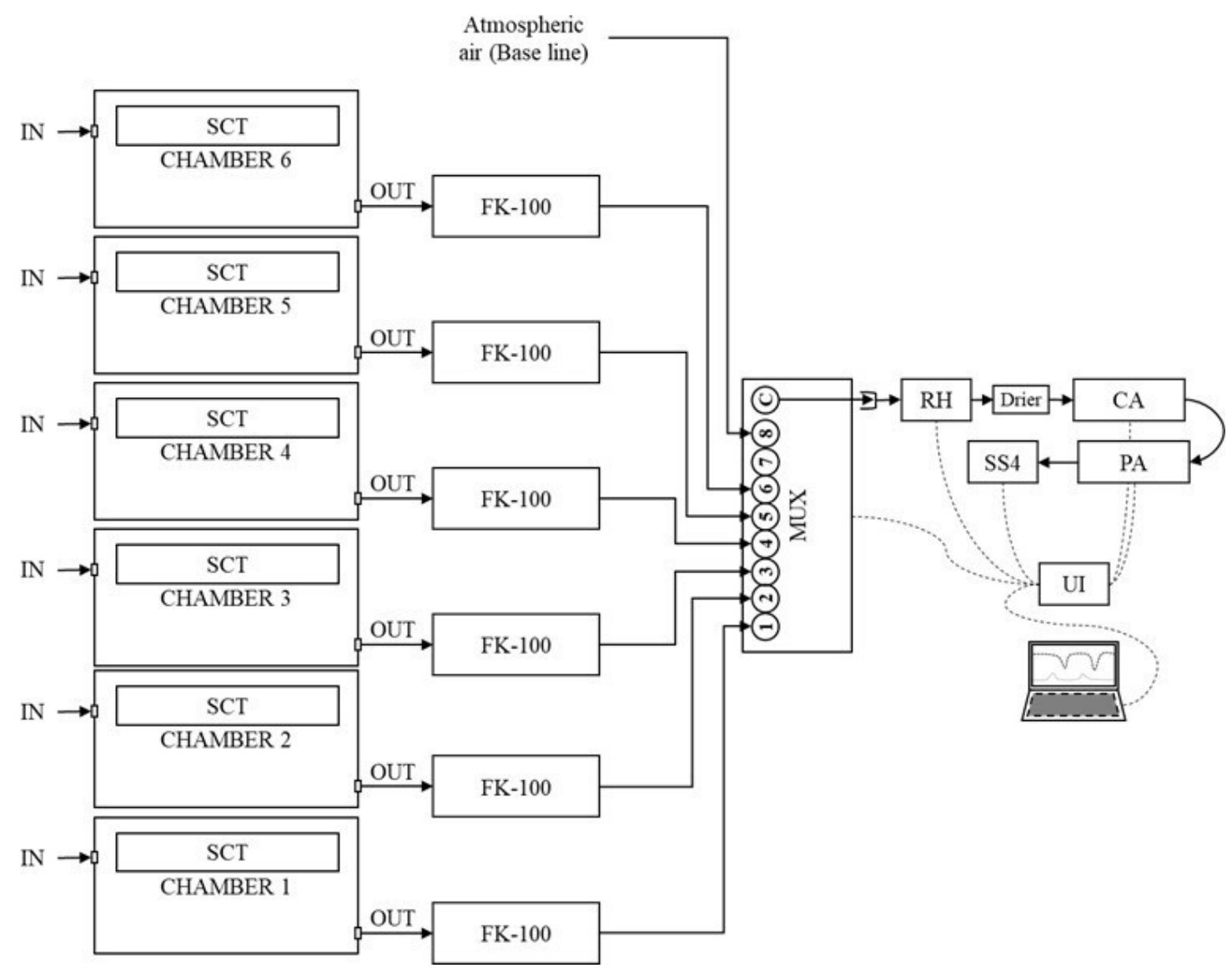

Figure 2. Components and operation diagram of the LAVINESP indirect calorimetry system. IN, air ingoing; SCT, temperature control system; OUT, air outgoing; FK-100, flow kit pump; MUX, Multiplexer (signal alternator); RH, Water vapor pressure analyzer; Drier, sample air drier; CA, carbon dioxide $\left(\mathrm{CO}_{2}\right)$ analyzer; PA, paramagnetic oxygen analyzer $\left(\mathrm{O}_{2}\right)$; SS4, sub-sampled air; UI, universal interface. Air flow direction $(\rightarrow)$ and data transference line (---).

gas concentrations were analyzed using a carbon dioxide analyzer $\left(\mathrm{CO}_{2}, \%\right)$, following the principle of non-dispersed infrared absorbance and oxygen $\left(\mathrm{O}_{2}, \%\right)$ using a paramagnetic sensor. The gas exchange measurement was recorded each second and averaged by minute for heat production calculations.

The gas exchange calculation was according to the Lighton [13] description for an open-circuit system. The in-going airflow $\left(\mathrm{F}_{\text {in }}\right)$ to the chamber, oxygen consumption $\left(\mathrm{VO}_{2}\right)$, and production of carbon dioxide $\left(\mathrm{VCO}_{2}\right)$ were computed according to the following calculations.

$$
\begin{aligned}
& \mathrm{F}_{\text {in }}(\mathrm{L} / \mathrm{min}) \\
& =\mathrm{F}_{\text {out }} \times\left(100-\left[\mathrm{O}_{2}\right]_{\text {out }}-\left[\mathrm{CO}_{2}\right]_{\text {out }}\right) /\left(100-\left[\mathrm{O}_{2}\right]_{\text {in }}-\left[\mathrm{CO}_{2}\right]_{\text {in }}\right) \\
& \mathrm{VO}_{2}(\mathrm{~L} / \mathrm{min})=\mathrm{F}_{\text {in }} \times\left[\mathrm{O}_{2}\right]_{\text {in }}-\mathrm{F}_{\text {out }} \times\left[\mathrm{O}_{2}\right]_{\text {out }} \\
& \mathrm{VCO}_{2}(\mathrm{~L} / \mathrm{min})=\mathrm{F}_{\text {out }} \times\left[\mathrm{O}_{2}\right]_{\text {out }}-\mathrm{F}_{\text {in }} \times\left[\mathrm{CO}_{2}\right]_{\text {in }}
\end{aligned}
$$

Where $\mathrm{F}_{\text {out }}$ is the outgoing airflow, $\left[\mathrm{O}_{2}\right]_{\text {in }}$ and $\left[\mathrm{CO}_{2}\right]_{\text {in }}$ are the atmospheric gas concentrations (baseline). $\mathrm{VO}_{2}$ and $\mathrm{VCO}_{2}$ were calculated from the corrected volume of gas at standard temperature and pressure dry and expressed by a unit of metabolic BW per day $\left(\mathrm{kg}^{0.75} / \mathrm{d}\right)$. The respiratory quotient (RQ) was calculated from $\mathrm{VCO}_{2} / \mathrm{VO}_{2}$, and the heat production (HP) was obtained by the Brouwer [14] equations:

$$
\mathrm{HP}\left(\mathrm{kJ} / \mathrm{kg}^{0.75} / \mathrm{d}\right)=16.18 \times \mathrm{VO}_{2}+5.02 \times \mathrm{VCO}_{2}
$$

\section{Body composition analyses}

After FHP measurements, lean mass (protein, water, and solute contents), lipid mass, and bone mineral content were analyzed for each bird in vivo using dual-energy X-ray absorptiometry (DEXA). The DEXA scanning procedure was done according to the validated procedure reported by Gonçalves et al [15]. The relative weight was expressed in grams of component per kilo of BW.

\section{Statistical analysis}

After the adaptation period, the BW was recorded at the beginning and finalized the fasting period. Then, the daily feed intake (before the fasting period), gas exchange parame- 
ters, heat production, and body composition were analyzed through one-way analysis of variance, considering a $95 \%$ confidence interval. The lineal additive model used for the response data were as follow:

$$
\mathrm{Y}_{\mathrm{ij}}=\mu+\tau_{\mathrm{i}}+\varepsilon_{\mathrm{ij}}
$$

Where: $Y_{\mathrm{ij}}$ is the observed variable, $\mu$ is the general mean, $\tau_{\mathrm{i}}$ is the treatment effect, and $\varepsilon_{\mathrm{ij}}$ is the experimental error.

The FHP, $\mathrm{RQ}, \mathrm{VO}_{2}$, and $\mathrm{VCO}_{2}$ of each bird (individually observed) and runs were calculated on the plateau phases of the HP behaviour during the fasting period. It was described around the last 8 hours of the fasting period (from 16 to 24 $h$ of the fasting).

A segmented model was fit to the HP during the fasting period, considering the individual observation of each treatment according to the following model:

$$
\mathrm{HP}=\mathrm{U} \times(\mathrm{t}<\mathrm{R}) \times(\mathrm{R}-\mathrm{t})+\mathrm{L}
$$

Where $\mathrm{U}$ is the decline rate of HP until time $\mathrm{R}$ (broken point), $\mathrm{L}$ is the plateau value of $\mathrm{HP}$ (plateau-FHP), and $\mathrm{t}$ is the time. It was made through the non-linear regression procedure aimed to reduce the error of fit.

All statistical analyses were performed using Minitab v.20 statistical software (Minitab Inc., StateCollege, PA, USA).

\section{RESULTS}

The performance parameters are shown in Table 1. At the beginning of the adaptation period to the treatments, the initial BW was similar between the birds distributed for each treatment ( $p>0.05$ ), with an average weight of $4.003 \pm 0.230$ $\mathrm{kg}$ for all birds. Also, the BW after the fasting period showed a tendency $(\mathrm{p}<0.10)$ to have a higher weight of birds fed ad libitum $(4.153 \pm 0.349 \mathrm{~kg})$ than birds under restricted feed $(3.839 \pm 0.160)$. On the other hand, weight variation between the beginning and the final fasting period was significantly different $(\mathrm{p}<0.01)$ between treatments. The ad libitum fed birds lost $53 \mathrm{~g}$ more than restricted treatment before $24 \mathrm{~h}$ of fasting. Additionally, the birds under ad libitum treatment significantly $(\mathrm{p}<0.01)$ increased daily feed intake by $17 \%$. Because ad libitum groups have free access to feed and water, a higher variation in feed intake on ad libitum treatments ( $\mathrm{SD}= \pm 13.12 \mathrm{~g}$ ) was observed compared to restricted groups (148 \pm 2.97$)$. Also, the feed intake under restricted regimen treatment was close to the amount of feed allocated.

The $\mathrm{VO}_{2}, \mathrm{VCO}_{2}$, and FHP were different $(\mathrm{p}<0.01)$ between treatments. Ad libitum birds have higher $\mathrm{VO}_{2}\left(+3 \mathrm{VO}_{2} / \mathrm{kg}^{0.75} / \mathrm{d}\right)$ and $\mathrm{VCO}_{2}\left(+2 \mathrm{VCO}_{2} / \mathrm{kg}^{0.75} / \mathrm{d}\right)$ consumption, and consequently higher FHP values $\left(+63 \mathrm{~kJ} / \mathrm{kg}^{0.75} / \mathrm{d}\right)$. However, the RQ was not different between treatments $(\mathrm{p}=0.490)$ (Table 2).

The body composition is presented in Table 3 . There was

\begin{tabular}{|c|c|c|c|c|}
\hline Treatment & Initial BW (g/bird) ${ }^{1)}$ & BW fasting $(\mathrm{g} / \mathrm{bird})^{2)}$ & BW variation $(\mathrm{g} / \mathrm{bird})^{3)}$ & $\mathrm{FI}(\mathrm{g} / \mathrm{bird})^{4)}$ \\
\hline Ad libitum & $4,021 \pm 257$ & $4,153 \pm 349$ & $216 \pm 19.73$ & $173 \pm 13.12$ \\
\hline Restricted & $3,985 \pm 225$ & $3,839 \pm 160$ & $163 \pm 15.41$ & $148 \pm 2.97$ \\
\hline$P$ & 0.803 & 0.073 & $<0.01$ & 0.001 \\
\hline RMSE & 241 & 271 & 17.706 & 9.515 \\
\hline
\end{tabular}

Table 1. Body weight and feed intake of broiler breeders with 30 weeks of age during the experimental period submitted to different feed regimens

The result was presented as $\mu \pm$ standard deviation.

BW, body weight; Fl, daily feed intake; P, probability; RMSE, root means square of the error.

1) Body weight at the start of the treatment adaptation period.

${ }^{2)}$ Body weight at the star the fasting period.

${ }^{3)}$ Difference between the initial and final body weight during the fasting period.

Table 2. Gas exchange parameters of oxygen consumption, $\mathrm{CO}_{2}$ production, respiratory quotient, and fasting heat production of broiler breeders

\begin{tabular}{|c|c|c|c|c|}
\hline Treatment & FHP $\left(\mathrm{kJ} / \mathrm{kg}^{0.75} / \mathrm{d}\right)$ & $\mathrm{RQ}\left(\mathrm{VCO}_{2} / \mathrm{VO}_{2}\right)$ & $\mathrm{VO}_{2}\left(\mathrm{~L} / \mathrm{kg}^{0.75} / \mathrm{d}\right)^{1)}$ & $\mathrm{VCO}_{2}\left(\mathrm{~L} / \mathrm{kg}^{0.75} / \mathrm{d}\right)^{2)}$ \\
\hline Ad libitum & $359 \pm 14.71$ & $0.779 \pm 0.033$ & $18 \pm 0.77$ & $14 \pm 0.668$ \\
\hline Restricted & $296 \pm 17.23$ & $0.804 \pm 0.079$ & $15 \pm 0.809$ & $12 \pm 1.317$ \\
\hline$P$ & $<0.010$ & 0.49 & $<0.010$ & 0.006 \\
\hline RMSE & 16.022 & 0.061 & 0.789 & 1.045 \\
\hline
\end{tabular}
submitted to the different feed regimens

The result was presented as $\mu \pm$ standard deviation. These values correspond to the last 8 hours of the fasting period (plateau of the heat production from 16 to 24 hours during the fasting period).

FHP, fasting heat production; RQ, respiratory quotient; P, probability; RMSE, root means square of the error.

${ }^{1)}$ Oxygen consumption.

${ }^{2)} \mathrm{CO}_{2}$ production. 
Table 3. Body composition (in $\mathrm{g} / \mathrm{kg}$ ) of broiler breeders submitted to different feed regimens

\begin{tabular}{lcccc}
\hline Treatment & BW $(\mathbf{g} / \mathbf{b i r d})^{\mathbf{1})}$ & Fat mass & Lean mass & BMC $\mathbf{( g / k g )}$ \\
\hline Ad libitum & $3,933 \pm 350$ & $194 \pm 28.6$ & $806 \pm 28.6$ & $20 \pm 1.866$ \\
Restricted & $3,617 \pm 205$ & $179 \pm 17.5$ & $818 \pm 19.38$ & $22 \pm 1.485$ \\
P & 0.085 & 0.278 & 0.408 & 0.045 \\
RMSE & 287 & 23.675 & 24.405 & 1.687 \\
\hline
\end{tabular}

The result was presented as $\mu \pm$ standard deviation.

BW, body weight; BMC, bone mineral content; P, probability; RMSE, root means square of the error.

${ }^{1)}$ Body weight value after fasting period.

no statistical difference in lipid and lean mass ( $p>0.05)$. However, bone mineral content was slightly different $(p=0.045)$, with $+2 \mathrm{~g} / \mathrm{kg}$ of bone mineral content on the birds submitted to restricted compared to ad libitum feeding regimen.

The broken line model was fit for each treatment, and the parameters are presented in Table 4 . Also, the $\mathrm{HP}\left(\mathrm{kJ} / \mathrm{kg}^{0.75} / \mathrm{d}\right)$ as a function of the time is illustrated in Figure 3. It was shown that the rate of energy expenditure declining after starting the fasting was higher on the ad libitum feeding, while the time to meet the broken point was the same, around $11 \mathrm{~h} 47$ min in both treatments. As a result, the plateau of FHP was $64 \mathrm{~kJ} / \mathrm{kg}^{0.75} / \mathrm{d}$ higher when the birds were fed ad libitum.

\section{DISCUSSION}

The thirteen days that the birds were submitted to ad libitum feeding resulted in a BW gain of 314 g per bird, representing $7.5 \%$ more from the initial BW. An important characteristic to be considered in broiler breeders, compared to other poultry categories, is that the birds present a growth even when they are adults and in production $[2,3]$. Thus, these birds are characterized as having multiphasic growth [16], explaining

Table 4. Parameters of the broken line model describe the metabolic rate variation $\left(\mathrm{kJ} / \mathrm{kg}^{0.75} / \mathrm{d}\right)$ along 24 hours of fasting of the broiler breeders previously submitted to different feed regimens

\begin{tabular}{lccccc}
\hline Treatment & Parameters & Estimate & Standard error & P & MSE \\
\hline Restricted & $\mathrm{U}\left(\mathrm{kJ} / \mathrm{d}^{2}\right)^{1)}$ & 7.00 & 1.544 & $<0.01$ & 439 \\
& $\mathrm{R}(\mathrm{h})^{2)}$ & 11.95 & 1.124 & & \\
Ad libitum & $\mathrm{L}\left(\mathrm{kJ} / \mathrm{kg}^{0.75} / \mathrm{d}\right)^{3)}$ & 300 & 2.619 & $<0.01$ & 533 \\
& $\mathrm{U}\left(\mathrm{kJ} / \mathrm{d}^{2}\right)$ & 10.05 & 1.417 & & \\
& $\mathrm{R}(\mathrm{h})$ & 11.63 & 0.726 & & \\
\hline
\end{tabular}

P, probability; MSE, mean square of the error.

Broken line model for the heat production in funtion of the time along the fasting period: $H P=U \times(t<R) \times(R-t)+L$

1) Rate of heat production decreasing after the feed was withdrawn.

2) Time of broken point.

${ }^{3)}$ Plateau value of FHP.

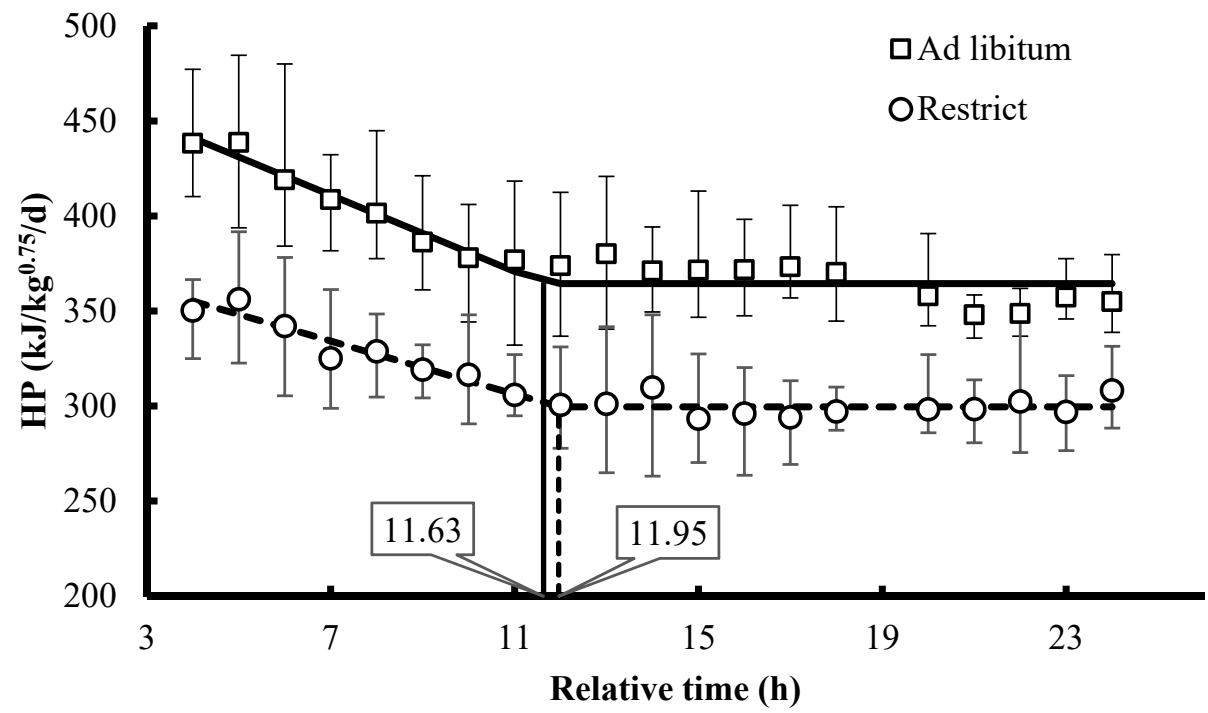

Figure 3. Broken line model $[H P=U \times(t<R) \times(R-t)+L]$ of $H P$ (heat production, $k J / k g .75 / d$ ) along of 24 hours of fasting period of broiler breeders previously submitted to feed regimen of ad libitum (-) and restricted (---). 
why they had different growth rates during the adaptation period on both feeding regimes due to the different amounts of nutrient intake. While the feed restriction induced a slight BW loss, as Caldas et al [17] observed between 33 to 37 weeks of age, the group fed ad libitum increased BW by $132 \mathrm{~g}$. Therefore, no control on feed intake and the BW can be carried to reproductive and sexual disorders affecting birds performance [1]. However, this depends on the length of the feed restriction period as hens can use body sources to recover nutrient needs for a certain period depending on the restriction level [2]. Also, under ad libitum feeding, with nutrient and energy intake above the recommendation [18], the individual feed intake variation leads to high variability in BW, making it difficult to get the flock's uniformity weight [19].

Gas exchange parameters have been scarcely described for broiler breeders during the production phase. For example, Caldas et al [17] reported recent results of 16.9 to $23 \mathrm{VO}_{2}$ and 15.4 to $21.9 \mathrm{~L} / \mathrm{kg}^{0.75} / \mathrm{d}$ for $\mathrm{VCO}_{2}$ measured in birds fed restricted programs. Also, the heat production ranged from 351 to $480 \mathrm{~kJ} / \mathrm{kg}^{0.75} / \mathrm{d}$, higher than we observed since the authors measures were conducted in fed birds, contrasted by the high RQ of 0.9 to 0.96 . On the other hand, Anderson and Kulp [20], who made measurements 18 to $20 \mathrm{~h}$ after the feed was withdrawn, reported similar values to our study, $\mathrm{VO}_{2}$ $\left(18.7 \mathrm{~L} / \mathrm{kg}^{0.75} / \mathrm{d}\right), \mathrm{VCO}_{2}\left(14.7 \mathrm{~L} / \mathrm{kg}^{0.75} / \mathrm{d}\right)$, and RQ (0.82); which was close to the FHP $\left(377 \mathrm{~kJ} / \mathrm{kg}^{0.75} / \mathrm{d}\right)$ of birds on ad libitum treatment.

Besides, Misson et al [21] reported the same values of heat production $\left(318 \mathrm{~kJ} / \mathrm{kg}^{0.75} / \mathrm{d}\right), \mathrm{VO}_{2}\left(16.1 \mathrm{~L} / \mathrm{kg}^{0.75} / \mathrm{d}\right)$, and $\mathrm{VCO}_{2}$ $\left(11.5 \mathrm{~L} / \mathrm{kg}^{0.75} / \mathrm{d}\right)$ as those observed in the present study in birds on feeding restriction. However, the RQ was different (0.72) for a $24 \mathrm{~h}$ period of fasting. This could be due to the another strain (Light Sussex) and productive level used by the mentioned authors, which was different from the present study [22]. According to Salas et al [23] and Attia et al [2], broiler breeders during the peak of production have a high protein catabolism rate to prioritize the egg formation. Even under fasting conditions, this period was not enough to interrupt the egg production; the birds mobilize body reserve to supply nutrients, mainly energy, to form the next egg. Thus, this explains why the oxidation of proteins occurs, which is used to synthesize the egg and induce a higher RQ value [24].

A feed restriction induced a basal metabolic rate reduction in growing swine due to the body mass reduction [25], in growing chicks [10] and, calves [26]. It was explained by Spratt et al [27], who mentioned that the FHP variation due to the visceral mass is only $4 \%$, and the significant fraction can be attributed to the body composition variation of around $30 \%$. However, the lean and fat mass was not affected by the feed regimen treatments. These results were similar to those reported by Caldas et al [17], where birds of 30 weeks old were described with tissue contents of $186 \mathrm{~g} / \mathrm{kg}$ for lean and $818 \mathrm{~g} / \mathrm{kg}$ for fat mass. While the bone mineral content reported was $14 \mathrm{~g} / \mathrm{kg}$ lower than those of our study. It is important to note that the methodology for determining body composition by DEXA has some limitations; lean mass is a conjunction between the protein and the water content that includes some mineral solutes. Therefore, it prevents a precise description of the actual value of body protein content since the water fraction is the factor that has more significant variability [28]. Additionally, DEXA is widely described by precision for determining mineral content. However, if there is a presence of an egg inside the animal, the mineral content would be influenced.

After feed deprivation in both groups, the metabolic rate behaviour was similar to reported by Zubair and Leeson [10] in 11 days-old broiler chicks, expressing a decline phases up to reach a minimum value described as plateau-FHP. Meanwhile, the broken point followed by the stable phases was reached at around $12 \mathrm{~h}$ of fasting in broiler breeders was not shown in growing birds. This metabolic phenomenon depends on the feed passage rate and gastrointestinal tract retention capacity, nutrient catabolism related to the body storage available, and demand for other metabolic functions. A significant reduction in HP is observed two hours after food deprivation due to the digestive tract is emptying, absorption of remaining nutrients, and metabolic adaptation to fasting conditions [26].

It was more evident in the ad libitum treatment, where birds presented a higher reduction of the heat production until the broken point. The time to reach the minimum stable phases of the heat production (or plateau-FHP) was the same between treatments. It is related to the feed intake amount and the bulk capacity of the broiler breeders. The broiler breeders bulk capacity is associated with the physicchemical composition of feed and water retention that affects the passage rate [29]. As the same feed was offered, the bulk capacity was similar between treatments. The plateau value of $\mathrm{HP}$ along the fasting time has shown a difference of 64 $\mathrm{kJ} / \mathrm{kg}^{0.75} / \mathrm{d}$ lower on the restricted birds group when compared with birds fed ad libitum. Similar results were observed by Zubair and Leeson [10], who reported a variation of 67 $\mathrm{kJ} / \mathrm{kg}^{0.75} / \mathrm{d}$ on fasting. It corresponds to the energy expenditure of the body mass metabolic activity [30].

\section{CONCLUSION}

Broiler breeders fed ad libitum had a high cost of basal energy expenditure and maintenance energy requirement in the production peak, without a variation in the body composition compared to those on restricted feeding. 


\section{CONFLICT OF INTEREST}

We certify that there is no conflict of interest with any financial organization regarding the material discussed in the manuscript.

\section{FUNDING}

This research was supported by public funding from Fundação de Amparo à Pesquisa do Estado de São Paulo (FAPESP) (Grant: 2019/26575-6, to N.K.S and 2019/26028-5 to G.F.S.T).

\section{ACKNOWLEDGMENTS}

This work is an undergraduate research thesis project in partial fulfilment of an undergraduate degree by Guilherme Ferreira S. Teofilo in the Faculty of Agricultural and Veterinarian Sciences of São Paulo State University - UNESP, SP, Brazil.

\section{REFERENCES}

1. Carneiro PRO, Lunedo R, Fernandez-Alarcon MF, Baldissera G, Freitas GG, Macari M. Effect of different feed restriction programs on the performance and reproductive traits of broiler breeders. Poult Sci 2019;98:4705-15. https://doi.org/ 10.3382/ps/pez181

2. Attia YA, Burke WH, Yamani KA, Jensen LS. Daily energy allotments and performance of broiler breeders.: 1 . males. Poult Sci 1995;74:247-60. https://doi.org/10.3382/ps.0740247

3. Attia YA, Burke WH, Yamani KA, Jensen LS. Daily energy allotments and performance of broiler breeders.: 2. Females. Poult Sci 1995;74:261-70. https://doi.org/10.3382/ps.0740261

4. Leksrisompong N, Romero-Sanchez H, Oviedo-Rondón EO, Brake J. Effect of feeder space during the growing and laying periods and the rate of feed increase at the onset of lay on broiler breeder female reproductive function. Poult Sci 2014;93:1599-607. https://doi.org/10.3382/ps.2013-03277

5. Pearson RA, Herron KM. Effects of energy and protein allowances during lay on the reproductive performance of broiler breeder hens. Br Poult Sci 1981;22:227-39. https:// doi.org/10.1080/00071688108447881

6. Renema RA, Robinson FE. Defining normal: comparison of feed restriction and full feeding of female broiler breeders. Worlds Poult Sci J 2004;60:508-22. https://doi.org/10.1079/ WPS200434

7. Bowling M, Forder R, Hughes RJ, Weaver S, Hynd PI. Effect of restricted feed intake in broiler breeder hens on their stress levels and the growth and immunology of their offspring. Transl Anim Sci 2018;2:263-71. https://doi.org/10.1093/tas/ txy064

8. De Beer M, Rosebrough RW, Russell BA, Poch SM, Richards
MP, Coon CN. An examination of the role of feeding regimens in regulating metabolism during the broiler breeder grower period. 1. Hepatic lipid metabolism. Poult Sci 2007;86:172638. https://doi.org/10.1093/ps/86.8.1726

9. Salas C, Ekmay RD, England J, Cerrate S, Coon CN. Effect of body weight and energy intake on body composition analysis of broiler breeder hens. Poult Sci 2019;98:796-802 . https://doi.org/10.3382/ps/pey377

10.Zubair AK, Leeson S. Effect of early feed restriction and realimentation on heat production and changes in sizes of digestive organs of male broilers. Poult Sci 1994;73:529-38. https://doi.org/10.3382/ps.0730529

11.Liu W, Cai H, Yan H, Liu G, Zhang S, Yang H. Effects of body weight on total heat production and fasting heat production in net energy evaluation of broilers. Chin J Anim Nutr 2014; 26:2118-25. https://doi.org/10.3969/j.issn.1006-267x.2014.08. 001

12.Noblet J, Dubois S, Lasnier J, et al. Fasting heat production and metabolic BW in group-housed broilers. Anim 2015;9: 1138-44. https://doi.org/10.1017/S1751731115000403

13. Lighton JRB. Measuring metabolic rates: a manual for scientists. Oxford University Press; 2008. https://doi.org/10.1093/acprof: oso/9780195310610.001.0001

14. Brouwer E. Report of sub-committee on constants and factors. In: Proceedings of the 3rd Symposium on Energy Metabolism of Farm Animals. European Association for Animal Production; 1965. vol 11. pp. 441-3.

15. Gonçalves CA, Sakomura NK, Pereira SE, Artoni SMB, Suzuki RM, Gous RM. Dual energy X-ray absorptiometry is a valid tool for assessing in vivo body composition of broilers. Anim Prod Sci 2018;59:993-1000. https://doi.org/10.1071/AN17637

16.Zuidhof MJ. Multiphasic poultry growth models: method and application. Poult Sci 2020;99:5607-14. https://doi.org/ 10.1016/j.psj.2020.08.049

17.Caldas JV, Hilton K, Boonsinchai N, England JA, Mauromoustakos A, Coon CN. Dynamics of nutrient utilization, heat production, and body composition in broiler breeder hens during egg production. Poult Sci 2018;97:2845-53. https://doi.org/10.3382/ps/pey133

18. Chaney LW, Fuller HL. The relation of obesity to egg production in broiler breeders. Poult Sci 1975;54:200-8. https:// doi.org/10.3382/ps.0540200

19.COBB. Guia de Manejo de Matrizes [internet]. Cobb-Vantress, Inc.; c2016 [cited 2016 Jun]. Available from: https://silo.tips/ download/guia-de-manejo-de-matrizes

20. Anderson RJ, Kulp WL. A study of the metabolism and respiratory exchange in poultry during vitamine starvation and polyneuritis. J Biol Chem 1922;52:69-89. https://doi.org/ 10.1016/S0021-9258(18)85853-7

21. Misson BH. An open circuit respirometer for metabolic studies on the domestic fowl: establishment of standard operating conditions. Br Poult Sci 1974;15:287-97. https://doi.org/10. 
1080/00071667408416109

22.Johnson RJ, Farrell DJ. Relationship between starvation heat production and body size in the domestic fowl. Br Poult Sci 1985;26:513-17. https://doi.org/10.1080/00071668508416842

23. Salas C, Ekmay RD, England J, Cerrate S, Coon CN. Determination of chicken body composition measured by dual energy X-ray absorptiometry. Int J Poult Sci 2012;11:462-8. https://doi.org/10.3923/ijps.2012.462.468

24.Gerrits WJJ, Van den Borne JJGC, Labussière E. Deriving heat production from the gaseous exchange: validity of the approach. Indirect calorimetry. Techniques, computations, and applications. Wageningen Academic Publishers, Wageningen, the Netherlands 2015;26:19-34. https://doi.org/10.3920/ 978-90-8686-809-4

25.Lovatto PA, Sauvant D, Noblet J, Dubois S, van Milgen J. Effects of feed restriction and subsequent refeeding on energy utilization in growing pigs. J Anim Sci 2006;84:3329-36. https:// doi.org/10.2527/jas.2006-048

26. Labussière E, van Milgen J, de Lange CF, Noblet J. Maintenance energy requirements of growing pigs and calves are influenced by feeding level. J Nutr 2011;141:1855-61. https://doi.org/10. 3945/jn.111.141291

27. Spratt RS, Bayley HS, McBride BW, Leeson S. Energy metabolism of broiler breeder hens.: 1 . The partition of dietary energy intake. Poult Sci 1990;69:1339-47. https://doi.org/10. 3382/ps.0691339

28. Alves WJ, Malheiros EB, Sakomura NK, et al. In vivo description of body growth and chemical components of egg-laying pullets. Livest Sci 2019;220:221-9. https://doi.org/10.1016/ j.livsci.2018.12.023

29. Nascimento MQ, Gous RM, Reis MP, Viana GS, Nogueira BRF, Sakomura NK. Gut capacity of broiler breeder hens. Br Poult Sci 2021;62:710-6. https://doi.org/10.1080/00071668. 2021.1912290

30.Kuenzel WJ, Kuenzel NT. Basal Metabolic rate in growing chicks gallus domesticus. Poult Sci 1977;56:619-27. https:// doi.org/10.3382/ps.0560619 